\title{
Rare Case of Bilateral Maxillary buccal exostosis in the anterior region of Libyan female patient: Case Report \& Literature Review
}

\author{
Huda Mohammed Aljalali ${ }^{1 *}$, Ali Mohammed Elmurtadi ${ }^{2}$ \\ ${ }^{1}$ Oral Biology Department- Faculty of Dentistry- University of Benghazi. Libya. \\ ${ }^{2}$ Oral Pathology and Medicine-Oral medicine department-Faculty of Dentistry-University of \\ Benghazi, Libya.
}

Received: 10 June 2019/ Accepted: 15 November 2019

Doi: https://doi.org/10.54172/mjsc.v34i3.274

\begin{abstract}
The buccalexostoses are broad-based, non-malignant surface growth occurring on the outer or facial surface of the maxilla and/or mandible, found usually in the premolar and/or molar regions, and rarely in the anterior region. A 35-years-old female patient seeks the dentist for a carious anterior tooth. On examination, bone exostosis on the buccal aspect of both quadrants of the maxillary arch was found. They are painless and may increase patient concern about poor esthetics, inability to perform oral hygiene procedures, and compromised periodontal health by causing food lodgment. The following article presents a very rare case of bilateral buccal-sided maxillary exostosis in the anterior region.
\end{abstract}

Keywords: Exsostosis, Libyan patient, case report.

\section{INTRODUCTION}

Tori and exostosis are nodular protuberances of calcified bone. They can be classified as torus mandibularis (TM), torus palatinus (TP), and buccal maxillary and mandibular exostosis (Medsinge et al., 2015). The most common types of intraoral osseous overgrowths are TP and TM (Antoniades, Belazi, \& Papanayiotou, 1998; Neville, Damm, Allen, \& Bouquot, 1995). The buccal maxillary exostoses are rare findings (Antoniades et al., 1998). The exostosis is most frequently seen in molars region, extending anteriorly sometimes as far as a second premolar and in rare cases, up to the canine and incisors region (Medsinge et al., 2015).

The maxilla has a higher prevalence rate of 5:1 in comparison to the mandible (Morrison M, et al. 2017). Most of the previous studies showed a higher rate of bucaalexostosis in males than females in ratio 6:1 (Antoniades et al., 1998; Medsinge et al., 2015). TP is a sessile, nodular bony mass commonly seen on the midline of the hard palate (Morrison $M$, et al. 2017). TM is a bony protuberance found on the lingual aspect of the mandible, in the canine and premolar region (Medsinge et al., 2015).

The buccalexostoses are multiple bony nodular masses found less frequently than tori. Some consider them a variation of normal anatomy rather than a disease, and they are usually painless (Gorsky, Raviv, Kfir, \& Moskona, 1996). The bilateral buccalexostosis occurs as bilateral, smooth bony growth along the facial aspect of the maxillary and/or mandibular alveolus. It is commonly found to appear in the premolar-molar region (Jainkittivong \& Langlais, 2000; Puttaswamaiah, Galgali, \& Gowda, 2011).

*Corresponding Author: Huda Mohammed Aljalali hudadentist@yahoo.com, Oral Biology Department, Faculty of Dentistry, University of Benghazi. Libya. 
The exact etiology is still not known, but it has been suggested that the bony overgrowth can be due to an abnormal increase in masticatory forces in the teeth (Jainkittivong \& Langlais, 2000). Compensatory response to the periodontal disease has been proposed to explain some cases of exostosis (Jainkittivong \& Langlais, 2000). The aim of this Study is to document the first case of bilateral bony exostosis in the anterior region seen in a Libyan patient and to review relevant literature about oral bony exostosis.

\section{CASE PRESENTATION}

A thirty five-years-old female Libyan patient reported to the dental clinic, Faculty of dentistry- University of Benghazi, for dental treatment of carious maxillary anterior tooth. On intraoral examination, dental caries was present in the upper lateral incisor. Bilateral bony overgrowth just above the canine region in the maxilla was seen (Figure 1). The patient noticed this overgrowth one month ago and did not increase in size, she had no history of any kind of symptoms associated with this region. She did not experience any discomfort or pain. The patient had no history of trauma in the involved area. However, She had a medical history of hyperthyroidism. She had also no family history of similar lesions.

On clinical examination, the oral cavity revealed bilateral round overgrowths with few centimeters located on the buccal aspect of the maxillary anterior region. On palpation, the lesions were small in size and bony-hard. The overlying mucosa was thin and blanched, and the generalized moderate periodontitis was observed. It did not interfere with speech, chewing or other oral functions. By electrical pulp tester, the adjacent teeth were vital and there was no history of pain or sensitivity.
Figure (1). Showing bilaterally maxillary exostosis in

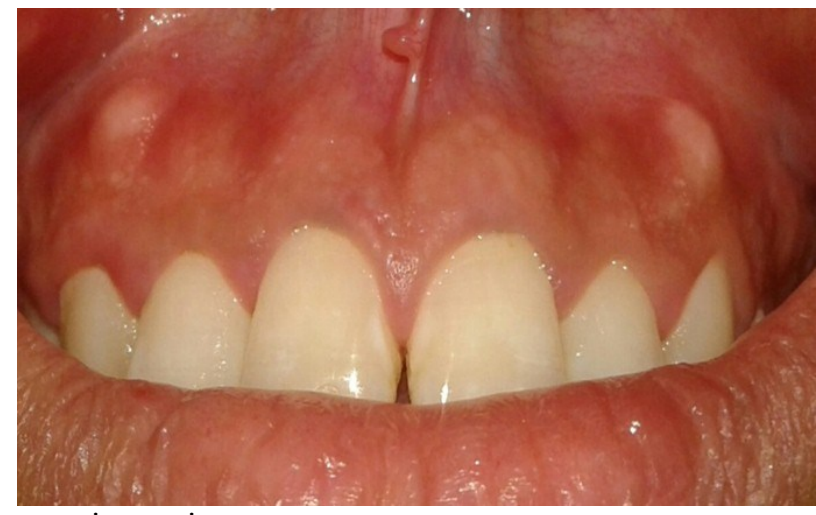

anterior region.

Radiographic examination showed a welldefined radiopaque area superimposing the roots of the anterior teeth (figure 2). These bony protuberances are caused by the thickening or enlargement of the cortical plate of the facial surface of the maxilla without any systemic abnormality helped to reach the diagnosis. 


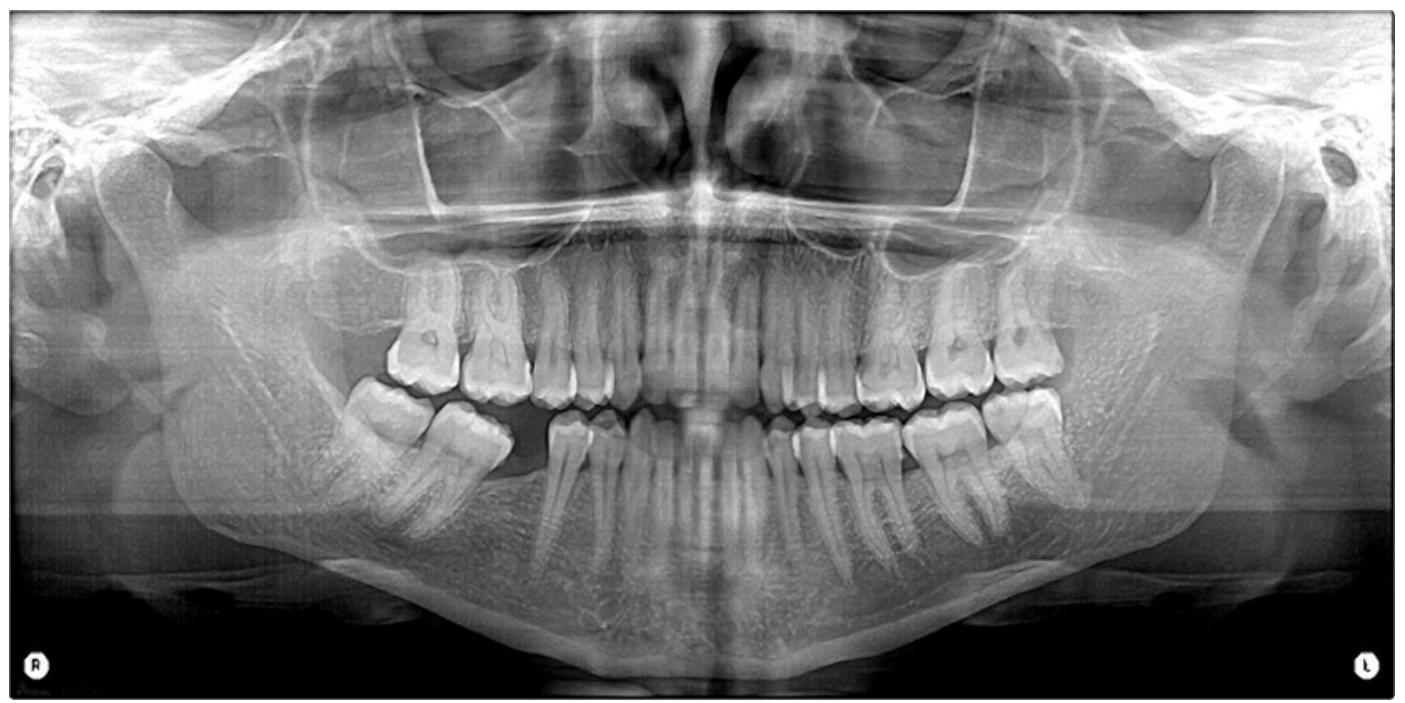

Figure (2). Radiographic picture for the buccal maxillary exostosis.

\section{DISCUSSION}

Multiple masses in the maxilla may represent multiple buccalexostosis, which are bony protuberances that arise from the cortical plates in the maxilla and mandible (Horning, Cohen, \& Neils, 2000). On palpation, the exostoses are bony hard protuberances, the overlying mucosa appears to be stretched but intact and normal in color, ulcerations may be seen as a result of any trauma to the mucosa. They usually occur in teenagers and early adulthood (Pechenkina \& Benfer Jr, 2002). It may continue to enlarge slowly over time. They are commonly self-limiting and painless. Their size may increase to several centimeters thus, contributing to the periodontal disease of adjoining teeth by retaining food during chewing instead of flushing away (Bouquot, 1998).

The exact etiology of the multiple exostosis remains unknown, some of the suggested causes include genetic factors, environmental factors, masticatory hyperfunction, bruxism (tooth clenching and grinding), injury, chronic irritation of a bone, a calcium-rich diet, excessive fish consumption, vitamin deficiency, sleep apnea, and temporomandibular joint dysfunction (Basha \& Dutt, 2011; Chaudhry, Tappuni, \& Challacombe, 2000;
Nery, Corn, \& Eisenstein, 1997), and it has been suggested to be the outcome of a mild, chronic periosteal inflammation (Bruce, Ndanu, \& Addo, 2004).

The histological features of tori and exostosis are identical (Bathla, 2011). A very small exostosis and tori consist entirely of compact bone, but when large and nodular it consists of a cancellous bone surrounded by cortical bone (Shamim, 2014).

The clinical examination along with radiographic interpretation will aid an exostosis diagnosis, the tori may appear as numerous rounded protuberances or calcified multiple lobules, whereas the exostosis is a single, smooth broad-based mass, which may have a sharp, pointed bony projection producing tenderness just beneath the mucosa (Smitha \& Smitha, 2015).

Exostosis may slowly enlarge up to centimeters in its greatest diameter, but it does not have malignant transformation potential (Tolstunov, 2009). Buccalexostoses are usually found only on the facial surface of the maxillary alveolar bone, especially in the posterior segment (Chaudhry et al., 2000).

On a radiograph, the exostosis appears as a well-defined round or oval calcified structure superimposing the roots of teeth. 
In our case, Gardner syndrome and fibrous dysplasia were considered in the differential diagnosis (Gorsky et al., 1996). Because of the lack of multiple polyposis of the large intestine, osteomas of the bones, multiple epidermoid or sebaceous cyst of the skin; particularly on the scalp and back; desmoid tumors, impacted supernumerary and permanent teeth, the Gardner syndrome was excluded (García-García, Martínez-González, Gómez-Font, Soto-Rivadeneira, \& OviedoRoldán, 2010; Morrison \& Tamimi, 2013; Palm, Franklin, \& Marklund, 2014).

Clinical findings of nodular protuberances on the buccal surface of the maxilla bilaterally below the mucobuccal fold in the anterior region over which the mucosa appeared blanched in the present case ruled out fibrous dysplasia. As, fibrous dysplasia is usually presented as painless swelling or bulging of the jaw with malaligned teeth (Chambrone \& Chambrone, 2005; Corsair, Iacono, \& Moss, 2001; Hassan, Alagl, \& Abdel-Hady, 2012).

Many of the previous studies showed that the diagnosis of a buccalexostosis is based on clinical and radiographic findings. An additional biopsy for diagnostic support is usually not recommended. However, sometimes a biopsy is required to exclude early osteosarcoma and chondrosarcoma (Echeverria, Montero, Abad, \& Gay, 2002; Islam, Cohen, Waite, \& Bhattacharyya, 2010).

Usually no treatment is required, but for those possibly affecting the periodontal condition, or when the protruberances cause pain or discomfort to the patient or these bony enlargements cause pseudo swelling over the lip, or becomes large enough to interfere with function denture placement, or cause recurring traumatic surface ulceration (usually from sharp food such as potato chips or fish bones) or as used to get autograft as it is a potent donor site, the conservative surgical excision can be performed. The bony mass may be removed using bone cutting bur or chiseled off through the base of the lesion (Aydin, Yildirim, \& Bozdemir, 2013; Chandna, Sachdeva, Kochar, \& Kapil, 2015; Siddiqui, Singh, Mishra, \& Mandal, 2017).

Most dental professionals recommend monitoring the areas with routine checkups. Routine cleansing of the areas above and below the bony projections can remove food particles that may become lodged in the irregular surfaces on the gum tissue (Chandna et al., 2015; Shamim, 2017). Swishing with a rinse, such as Colgate Total Advanced Health mouthwash, which removes more bacteria for a healthier mouth.(Shamim, 2017).

\section{CONCLUSION}

This is a unique and a rare presentation of exostosis on the buccal side of the maxillary anterior region, bilaterally in hyperthyroidism patient. Although exostosis is rarely found in the anterior region of the facial surface of the maxilla, it should not be ignored and should be carefully included in the differential diagnosis of bony hard swelling in the anterior region.

\section{REFERENCES}

Antoniades, D. Z., Belazi, M., \& Papanayiotou, P. (1998). Concurrence of torus palatinus with palatal and buccal exostoses: case report and review of the literature. Oral Surgery, Oral Medicine, Oral Pathology, Oral Radiology, and Endodontology, 85(5), 552-557.

Aydin, U., Yildirim, D., \& Bozdemir, E. (2013). Subpontic osseous hyperplasia: Three case reports and literature review. European journal of dentistry, 7(3), 363.

Basha, S., \& Dutt, S. C. (2011). Buccal-sided mandibular angle exostosis-A rare case 
report. Contemporary clinical dentistry, 2(3), 237.

Bathla, S. (2011). Periodontics revisited: JP Medical Ltd.

Bouquot, J. (1998). Bond's Book of Oral Diseases: Philadelphia: ChurchillLivingstone.

Bruce, I., Ndanu, T., \& Addo, M. (2004). Epidemiological aspects of oral tori in a Ghanaian community. International dental journal, 54(2), 78-82.

Chambrone, L., \& Chambrone, L. (2005). Bony exostoses developed subsequent to free gingival grafts: case series. British dental journal, 199(3), 146.

Chandna, S., Sachdeva, S., Kochar, D., \& Kapil, H. (2015). Surgical management of the bilateral maxillary buccal exostosis. Journal of Indian Society of Periodontology, 19(3), 352.

Chaudhry, S., Tappuni, A., \& Challacombe, S. (2000). Multiple maxillary and mandibular exostoses associated with multiple dermatofibromasA case report. Oral Surgery, Oral Medicine, Oral Pathology, Oral Radiology, and Endodontology, 89(3), 319-322.

Corsair, A., Iacono, V., \& Moss, S. (2001). Exostosis following a subepithelial connective tissue graft. Journal of the International Academy of Periodontology, 3(2), 38-41.

Echeverria, J. J., Montero, M., Abad, D., \& Gay, C. (2002). Exostosis following a free gingival graft. Journal of Clinical Periodontology: Case Report, 29(5), 474-477.

García-García, A. S., Martínez-González, J.M., Gómez-Font, R., Soto-Rivadeneira,
Á., \& Oviedo-Roldán, L. (2010). Current status of the torus palatinus and torus mandibularis. Med Oral Patol Oral Cir Bucal, 15(2), e353-360.

Gorsky, M., Raviv, M., Kfir, E., \& Moskona, D. (1996). Prevalence of torus palatinus in a population of young and adult Israelis. Archives of oral biology, 41(6), 623-625.

Hassan, K., Alagl, A., \& Abdel-Hady, A. (2012). Torus mandibularis bone chips combined with platelet rich plasma gel for treatment of intrabony osseous defects: clinical and radiographic evaluation. International journal of oral and maxillofacial surgery, 41(12), 1519-1526.

Horning, G. M., Cohen, M. E., \& Neils, T. A. (2000). Buccal alveolar exostoses: prevalence, characteristics, and evidence for buttressing bone formation. Journal of periodontology, 71(6), 1032-1042.

Islam, M. N., Cohen, D. M., Waite, M. T., \& Bhattacharyya, I. (2010). Three cases of subpontic osseous hyperplasia of the mandible: A report. Quintessence International, 41(4).

Jainkittivong, A., \& Langlais, R. P. (2000). Buccal and palatal exostoses: prevalence and concurrence with tori. Oral Surgery, Oral Medicine, Oral Pathology, Oral Radiology, and Endodontology, 90(1), 48-53.

Medsinge, S. V., Kohad, R., Budhiraja, H., Singh, A., Gurha, S., \& Sharma, A. (2015). Buccal exostosis: a rare entity. Journal of international oral health: $\mathrm{JIOH}, 7(5), 62$.

Morrison, M. D., \& Tamimi, F. (2013). Oral tori are associated with local 
mechanical and systemic factors: a case-control study. Journal of Oral and Maxillofacial Surgery, 71(1), 14-22.

Morrison M(2017). Exostosis :types, causes, and treatment: Journal of international oral health.(9):34-38.

Nery, E. B., Corn, H., \& Eisenstein, I. L. (1997). Palatal exostosis in the molar region. Journal of periodontology, 48(10), 663-666.

Neville, B. W., Damm, D. D., Allen, C. M., \& Bouquot, J. E. (1995). Oral and Maxillofacial Pathology. 2 [sup] nd ed. Philadelphia, PA: Saunders, 337-369.

Palm, E., Franklin, K. A., \& Marklund, M. (2014). Mandibular tori size is related to obstructive sleep apnea and treatment success with an oral appliance. Sleep and Breathing, 18(2), 431-438.

Pechenkina, E. A., \& Benfer Jr, R. A. (2002). The role of occlusal stress and gingival infection in the formation of exostoses on mandible and maxilla from Neolithic China. Homo, 53(2), 112-130.

Puttaswamaiah, R. N., Galgali, S. R., \& Gowda, V. S. (2011). Exostosis: A donor site for autograft. Indian Journal of Dental Research, 22(6), 860.

Shamim, T. (2014). The psychosomatic disorders pertaining to dental practice with revised working type classification. The Korean journal of pain, 27(1), 16.

Shamim, T. (2017). Bilateral maxillary and mandibular buccal exostosis: a self reported case and a proposal to include buccal exostosis under miscellaneous disorders of revised working classification of the psychosomatic disorders pertaining to dental practice.
The Korean journal of pain, 30(2), 151152.

Siddiqui, H., Singh, D. K., Mishra, S., \& Mandal, A. (2017). Bilateral buccal exostosis evaluated by cone-beam computed tomography: A rare accidental finding. Indian Journal of Dental Sciences, 9(1), 34.

Smitha, K., \& Smitha, G. (2015). Alveolar exostosis-revisited: a narrative review of the literature. The Saudi Journal for Dental Research, 6(1), 67-72.

Tolstunov, L. (2009). Maxillary tuberosity block bone graft: innovative technique and case report. Journal of Oral and Maxillofacial Surgery, 67(8), 17231729. 
حالة نادرة من Exostosis الثنائي الثوكي في المنطقة الأمامية للمريض الليبي: تقرير حالة

$$
\begin{aligned}
& \text { هاى محمد الجلالي"*3 ، محد علي المرتضى } 2
\end{aligned}
$$

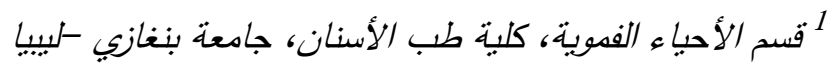

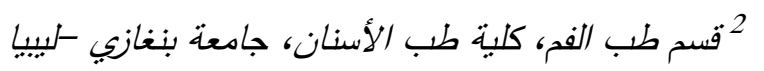

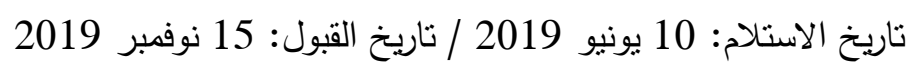
https://doi.org/10.54172/mjsc.v34i3.274:Doi

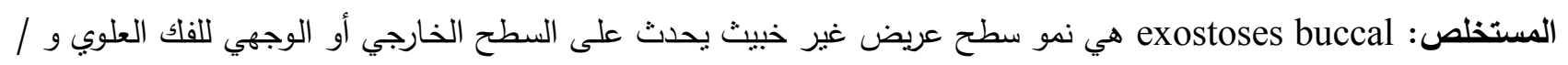

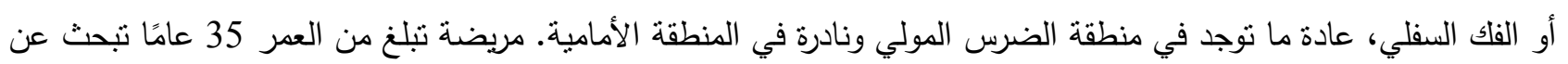

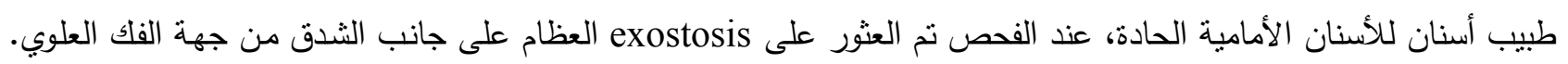

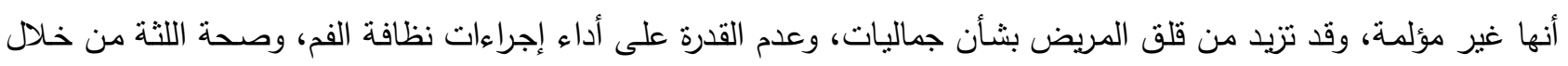

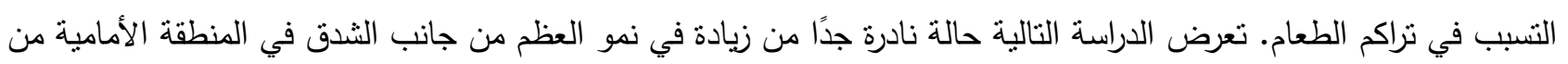
الفاك العلوي. الكلمات المفتاحية: الربوخ، مريض ليبي، تقرير حالة. 